\title{
ECCE HOMO, SCIENTIA CLARUS: LUIS FOURNIER ORIGGI (1935-2002)
}

\author{
Carlos O. Morales \\ Escuela de Biología, Universidad de Costa Rica. 2060 San José, Costa Rica \\ y Jardín Botánico Lankester. Apdo. 1031-7050 Cartago, Costa Rica
}

¡He allí al hombre, conocido por su sabiduría! Esta frase latina del título resume mi memoria del Dr. Luis Alberto Fournier Origgi, eminente ecólogo, botánico y agrónomo de la Universidad de Costa Rica (U.C.R.) fallecido sorpresivamente el pasado 5 de julio. La gran labor científica y agronómica del Dr. Fournier pasó desapercibida para muchos, porque él nunca buscó imagen o renombre. Fue un científico, un docente y un humanista, que transmitía a los estudiantes conocimientos y experiencias, como muy pocas personas pueden lograrlo. En clases y conferencias, como un estímulo para los estudiantes, él citaba al poeta latino Virgilio: "Felix qui potuit rerum cognoscere causas"; es decir, feliz quien ha podido conocer las causas de las cosas. Don Luis fue, sin duda, uno de esos seres afortunados que lograron entender el mundo mucho más allá de lo común.

Él se graduó de Ingeniero Agrónomo en la U.C.R. en 1958. En 1961 obtuvo el título de Magister Agriculturae en el Instituto Interamericano de Ciencias Agrícolas de la O.E.A. La Universidad de California en Davis le confirió el grado de Ph.D. en Botánica en 1964. De regreso a la U.C.R., en la Escuela de Biología hizo grandes contribuciones para forjar el Herbario de la Universidad de Costa Rica (USJ), que había sufrido los estragos de un incendio el 20 de marzo de 1965. Además, la U.C.R. tuvo en él a uno de sus más destacados docentes e investigadores en ciencias biológicas desde 1959 hasta 1988. En este año Don Luis se pensionó, pero siguió colaborando activamente con la Escuela de Biología como Profesor Emérito hasta el día de su muerte.

Don Luis ha dejado profundas huellas en varias áreas, tales como la ecología forestal, el pensamiento conservacionista y la investigación agronómica (cultivo del café). Décadas de estudios y observaciones le permitieron comprender mejor que nadie, en la zona neotropical, los problemas ambientales y el desarrollo de bosques en áreas degradadas por actividades antropógenas. A lo largo de 37 años de persistentes y rigurosas observaciones en sus fincas de Ciudad Colón y Tabarcia, él protegió áreas que se convirtieron, con el paso del tiempo, en bosques exuberantes con una diversidad comparable a la que mostraban los antiguos bosques que fueron destruidos. La gran magnitud del legado científico y académico de Don Luis se percibe en sus cerca de 150 publicaciones, que incluyen tesis, artículos científicos y varios libros. Una de sus publicaciones botánicas sobresalientes es Botany of Cocos Island, Costa Rica, que es un capítulo del libro The Galápagos, editado por R.I. Bowman y publicado en 1966 por la Universidad de California. El martes 9 de julio, cuando velamos en la Escuela de Biología las cenizas de Don Luis, logramos cubrir todas las mesas de un extenso laboratorio con muchas de sus publicaciones, lo que reflejó claramente cuán fructífera fue su vida científica y académica.

Una sólida formación académica y científica se complementaba con una profunda cultura y un gran sentido de humanismo, reflejado en su calidad humana incomparable. Por su clara conciencia histórica, Don Luis poseía un vastísimo conocimiento del desarrollo de las ciencias. Una semana antes de su muerte ofreció, en la Escuela de Biología, un coloquio sobre los "Antecedentes de la investigación biológica en Costa Rica", exponiendo las raíces en la antigua Grecia y culminando en las décadas recientes de la historia de la biología en Costa Rica. Nos queda en el recuerdo, como una lección de rectitud, lo que Don Luis le dijo al M.Sc. Rodolfo Ortiz cuando éste empezó a trabajar en la U.C.R.: "Rodolfo, sírvale a la Universidad, pero no se sirva de ella". 
Con un apellido francés y otro italiano, Don Luis me contó, hace varios años, que también tenía una abuela alemana. Él sintió siempre gran admiración y estima por la cultura y las ciencias alemanas. Su conciencia preclara siempre estuvo atenta en busca de la verdad y del saber, máximos ideales a los que puede aspirar un espíritu universitario. Como recuerdo imborrable del Dr. Fournier tenemos una especie pteridófita de Costa Rica y Panamá: Elaphoglossum fournierianum L.D. Gómez, Revista Biol. Trop. 20: 33. 1972. 